\title{
Cross-cultural Experiences during a Visiting Scholar Program: “...A Start[ing] not a Finishing Point”
}

\author{
Carla AA Ventura \\ University of São Paulo at Ribeirão Preto College of Nursing, caaventu@eerp.usp.br \\ Judith E. Mill \\ University of Alberta, judy.mill@ualberta.ca \\ Isabel A.C. Mendes \\ University of São Paulo at Ribeirão Preto College of Nursing, iamendes@usp.br \\ Emanuele Seicenti de Brito \\ University of Sao Paulo, emanuele600@gmail.com \\ Leanne Johnson \\ University of Alberta, leanne.johnson@ualberta.ca
}

Follow this and additional works at: https://qane-afı.casn.ca/journal

Part of the Bilingual, Multilingual, and Multicultural Education Commons, Educational Assessment, Evaluation, and Research Commons, Other Teacher Education and Professional Development Commons, and the University Extension Commons

\section{Recommended Citation}

Ventura, Carla AA; Mill, Judith E.; Mendes, Isabel A.C.; de Brito, Emanuele Seicenti; and Johnson, Leanne (2017) "Cross-cultural Experiences during a Visiting Scholar Program: “...A Start[ing] not a Finishing Point”," Quality Advancement in Nursing Education - Avancées en formation infirmière: Vol. 3: Iss. 1, Article 8.

DOI: https://doi.org/10.17483/2368-6669.1095

This International Perspective is brought to you for free and open access by Quality Advancement in Nursing Education Avancées en formation infirmière. It has been accepted for inclusion in Quality Advancement in Nursing Education - Avancées en formation infirmière by an authorized editor of Quality Advancement in Nursing Education - Avancées en formation infirmière. 


\section{Cross-cultural Experiences during a Visiting Scholar Program: “...A Start[ing] not a Finishing Point"}

\section{Cover Page Footnote}

We would like to acknowledge the generous donation of Mr. Gordon Arnell to initiate the program in 2004. The research team would like to acknowledge the contributions of Dayna Kliachik who conducted the interviews and coded the data at the UA site. Nous aimerions remercier M. Gordon Arnell pour son généreux don permettant de lancer le programme en 2004. L'équipe de recherche voudrait également souligner la contribution de Mme Dayna Kliachik, qui a réalisé les entretiens et effectué le codage des données au site de l'UA. 


\section{Introduction}

Nursing faculties across the globe increasingly recognize the importance of creative university partnerships to enrich knowledge and understanding about cultural, economic, political, social and technological forces which affect local and global nursing (Kulbok, Mitchell, Glick, \& Greiner, 2012). In 2004, a Visiting Scholar Program (VSP) was developed between the Faculty of Nursing, University of Alberta (UA), Canada, and the University of São Paulo at Ribeirão Preto College of Nursing (USP-EERP), Brazil, based on an existing partnership (Mill et al., 2012). The primary goal of the VSP was to promote capacity building among nurse researchers and to enhance the production of knowledge to influence policy and practice in Brazil (Mill et al., 2012). The VSP was made possible through a donation from a private donor to enable faculty and student mobility programs and exchanges, joint research activities and publications, faculty development and capacity building. In order to achieve this, one pivotal strategy of the program was to provide a fellowship to junior faculty members at USP-EERP who had completed their $\mathrm{PhD}$ in the five years prior to their application.

Each year, program managers in both universities negotiated the criteria to be followed, potential VSP candidates and supervisors, and candidates' goals in terms of the research focus and supervisor availability. Scholars who wished to participate in the VSP initiated the process through discussions with their department head, program manager and the Dean at USP-EERP. Once given approval to participate in the VSP, the scholar contacted the UA to assist with the selection of a supervisor. Following this, the scholars began developing their research proposal in partnership with their supervisors. During their time at UA, in addition to the development of their research project, visiting scholars were enrolled in 14 weeks of English language training.

Typically, research to evaluate international exchanges such as the VSP focuses on only one of the partner institutions or on the perspective of students or scholars. Relatively few researchers have conducted collaborative studies with other institutions to explore the experiences of participants and to provide a more in-depth analysis of the international program (Button, Green, Tengnah, Johansson, \& Baker, 2005). In addition, several authors have described the development of cultural competence among students following participation in international exchange programs (Hagen, Munkhondya, \& Myhre, 2009; Kuehn et al., 2011). However, there is a gap in the literature regarding the development of intercultural competencies among faculty members from different countries and institutions.

In this paper, culture is considered the totality of socially transmitted behavioural patterns, arts, beliefs, values, customs, life-ways and all other products of human work. Culture is a characteristic of a population and guides individuals worldviews and decision making (Purnell \& Paulanka, 1998). Cultural competence is generally understood as a developmental process of personal maturation, whereby the learner moves from lower to higher levels of intercultural awareness that includes self-awareness and the capacity to act in culturally diverse contexts (Koskinen et al., 2009; Koskinen \& Tossavainen, 2004).

The growing awareness and maturation that occurs as a result of the adjustment to differences are fundamental to becoming interculturally competent (Koskinen \& Tossavainen, 2004). According to Bennet (1993) cultures can only be understood relative to one another and a particular behaviour can only be understood within a cultural context. During a cross-cultural exchange program, participants are immersed in a foreign culture and language over an extended period of time, which offers them a potential opportunity to develop intercultural competencies. 


\section{The study}

Aim

The purpose of this paper is to describe the VSP as a context for cross-cultural learning experiences. Furthermore, considering that there is limited research to describe the benefits and challenges of international programs for nursing faculty, this article focuses on the cross-cultural experiences and the development of intercultural competencies described by scholars and supervisors involved with the VSP nursing program in Canada and Brazil. Findings related to the scholarly outcomes of participation in the VSP have been published elsewhere (Mill, Johnson, Mendes, Ventura, \& Brito, 2014).

\section{Design}

The Visiting Scholar Program was evaluated between January and June 2011. A descriptive qualitative approach (Sandelowski, 2000) was the design used to evaluate the program.

\section{Participants}

Scholars, supervisors, and staff members from UA and USP-EERP who had been involved with the VSP participated in the research.

\section{Data Collection}

Data were collected through individual semi-structured in-depth interviews. The interviews were digitally recorded and transcribed. At each site, a research assistant conducted the interviews with supervisors and scholars under the supervision of a member of the research team. Each interview took approximately 30 to 60 minutes to complete.

\section{Ethical Considerations}

Approval to conduct the evaluation at UA was obtained from the Health Research Ethics Board and from the Ethics Board at the USP-EERP. In addition, participants signed an informed consent. In order to protect the anonymity of the participants, they are identified by number and as "staff", "supervisor", "visiting scholar", "graduate student", or "Dean".

\section{Data Analysis}

An inductive process was used to analyze the data, following Morse's (1994) taxonomy including comprehending, synthesizing, theorizing and re-contextualizing the data during face to face and virtual meetings among the authors. In this study, comprehension of the culture was achieved through the literature review and was enhanced by having investigators from both countries. Synthesizing refers to sorting significant from insignificant findings in order to begin to develop a composite description. A coding framework was developed using a small subset of the interviews with input from investigators and research assistants in each of the study countries to assist with the identification of key themes and synthesize the findings. As the analysis process proceeded, the coding framework was refined to reflect the new insights about the data and the relationship among the categories. Theorizing and re-contextualizing the findings involved the process of linking the findings to established knowledge and took place during virtual and face to face research team meetings. 


\section{Rigour}

At the UA, the interviews were carried out in English while at USP-EERP the interviews were carried out in Portuguese and translated verbatim into English for analysis. The process, referred to as back translation (Choi, Kushner, Mill, \& Lai, 2012; Smith, Bond, \& Kâğıtçıbaş1, 2006), was carried out by an independent translator fluent in both English and Portuguese. Once the translation was completed, the first author, also fluent in English and Portuguese, checked the transcripts for accuracy.

\section{Findings}

A total of 35 individuals participated over the seven years of the study: 16 in Brazil and 19 in Canada. Brazilian participants included twelve former scholars, two staff members from the International Office, one graduate student, and one former Dean at USP-EERP. In Canada, twelve supervisors and five staff working with the project participated in an interview at UA and two provided email feedback. One supervisor declined an interview and one did not respond to the request for an interview. The participating scholars stayed in Edmonton an average of 6.4 months, with a range of six months to one year. The scholars had completed their doctoral education between one to ten years prior to beginning the VSP; their research covered a wide range of topics including infectious chronic illness, maternal child health, nursing management, pediatrics, public health, medical nursing, education, ethics and mental health nursing. Although scholars typically must complete their PhD in the five years prior to beginning post-doctoral studies, two of the scholars from USP-EERP had not had the opportunity to apply for postdoctoral studies, and therefore it had been more than five years since the completion of their $\mathrm{PhD}$.

\section{Cross-Cultural Learning Process}

Based on the analysis of the findings related to the development of intercultural competencies, the "Cross-Cultural Learning Process" was the central theme, with benefits, challenges, and lessons learned emerging as the sub-themes.

\section{Benefits.}

Supervisors and scholars both described personal and professional benefits as a result of their participation in the VSP. As one supervisor stated, "I think it was worthwhile in a sense of coming to gain some knowledge about what was happening in South America...I was quite impressed with what was happening there, and then seeing the kinds of linkages that were so important for both universities". When asked how the VSP experience had impacted their careers, the supervisors described a range of benefits. Most supervisors felt that working with the scholars brought more depth to their own research programs, "seeing beyond high-income countries here in North America to the broader lower middle-income countries because it's essential that knowledge from what we are doing in Canada influences what goes on there".

The scholars outlined progress and positive outcomes in relation to their research, teaching and community service. They described a wide range of benefits to their research programs as a result of participating in the VSP: the development of specific research skills, 
including methodological expertise; increased understanding of the research process; and connections to their supervisors' research networks. One scholar shared:

From a research perspective, [my] experiences entailed significant gains in the methodological learning process. So, particularly what I'm concerned, my very important gain was to apprehend a specific method, which even permitted the publication together with the supervisor there (Visiting Scholar \#7).

Although the development of teaching skills was not a specific goal of the VSP, many scholars were able to observe undergraduate and graduate teaching while at UA. This made them reflect on their own teaching practice and the possibilities to introduce different approaches to their teaching:

He made me reflect on an educative intervention strategy for people with diabetes, people I work with in [my] research, teaching and community service. He made me reflect on that learning method for patients with chronic illnesses (Visiting Scholar \#3).

I improved some methodological aspects and consequently, this affects teaching and community service (Visiting Scholar \#3).

As my supervisor came from the education area, I had the opportunity to experience some distinguished processes, like, which she ended up using in the classroom with the nursing students. So it only increased my list of possibilities to work with the students too (Visiting Scholar \#8).

Concerning teaching, in the subject, I am bringing my post-doctoral supervisor [to Brazil], so she is going to help us in a graduate subject, and I've changed that subject a bit this year, me and my colleagues [...], I tried to do a bit like they do it there in Canada (Visiting Scholar \#9).

\section{Challenges.}

Challenges described by the participants were mainly related to language barriers and acclimatization to the Canadian culture, particularly following arrival. Many supervisors were aware of how difficult it was to adapt to a different culture, especially when scholars were not able to communicate well in English. Thus, the Canadian supervisors felt that their colleagues needed increased awareness and tolerance regarding cultural adaptation issues. Supervisors, staff, and scholars commented on the challenges adapting to the culture, particularly to the acquisition of English language skills:

The initial adaptation process was very difficult, primarily because of the language, so our language difficulties are very big when we arrived there, even if you have studied English it's very different (Visiting Scholar \#10).

Concerning the language, the first month is very difficult, but afterwards, over time, you start to gain some greater fluency to speak and understand. But, to develop the language, six months is very short (Visiting Scholar \#4).

Well, I think the main difficulty is and continues being the candidates' English language skills and lack of cultural preparation for this kind of experience (Staff \#1).

They've left their home, their family, their language, their culture, everything. They usually arrive in the middle of winter. It's very hard (Supervisor \#2). 
Supervisors noted that the acclimatization and adaptation process decreased the scholar's productivity and a longer stay in Canada was suggested to compensate for the time required to acclimatize. One supervisor commented, "acclimatization to the culture here and learning English, which is a huge thing for them, gobbles up so much of their time that they've almost gone back before they're really finished developing their research study".

Another important issue related to the acclimatization process was accommodation. Initially, the scholars without children were billeted throughout the city or lived in apartments. Early in the VSP, a few scholars were located a long distance from the university which presented some challenges.

One supervisor described the challenges that the scholar she worked with faced living a long distance from the UA campus:

So if she stayed and worked late at night, then the buses, the schedule is not very convenient, so she would wind up being a half an hour at [bus transfer station], waiting for the next bus to take her to [community in south Edmonton]. So I do remember her saying that she would have found it much easier if the housing was closer to the university (Supervisor \#11).

A scholar also described this challenge; however, once she moved closer to the university, the acclimatization process significantly improved:

The process was kind of difficult, but that was expected. The problem was that, I went there to study and used to spend three hours on transportation every day, which means that that really hampered me at first. It was an adaptation period, and I lived very far off, that is, I didn't know anything. So that was a bit traumatic because I wanted to study, I wanted to get involved in activities, and I lived very far, I couldn't stay long, until very late because the neighbourhood where I lived was dangerous, so I couldn't arrive home very late. But that was reconsidered because I changed homes. But, then, it was easy to adapt then, and I was there to study, to learn, and this ended up irrelevant, this adaptation thing (Visiting Scholar \# 3).

Subsequent to learning about this issue, the Global Nursing Office at UA tried to locate scholars closer to the university; however, this often meant higher priced accommodation. In this context, supervisors felt that there was a need to ensure that the billeting family was chosen appropriately and that the scholars lived in a healthy and positive environment. This was a priority for the Global Nursing Office when living arrangements were considered. In addition, the inclusion of children often required alternate housing arrangements, and at times day care and school placements needed to be made. Staff experienced some logistical challenges with these arrangements:

If they come with children, it makes it even more challenging because a lot of places will not take children. So a lot of it depends on the person who is coming and how enterprising they are, how willing they are to experience something they've never experienced before, how they can live with uncertainty (Staff \#1).

Since the initiation of the VSP in 2004, an increasing number of scholars have brought their children with them. Some supervisors felt that in these cases the acclimatization was facilitated, as the scholars were less likely to experience feelings of loneliness when their families accompanied them. The additional financial costs associated with supporting a family in 
Edmonton, however, made it difficult for the scholars with families to extend their stay at UA. Despite challenges related to accommodating families, participants commented on the benefits for scholars when children accompanied them:

I think it's an enriching experience for the family. And, it would be a shame to limit access to specifically women who don't have children (Supervisor \#1).

Now that folks are bringing their children, I think that's way better because the first ones who came that left their children and husbands, partners, whatever behind, were terribly lonely (Staff \#3).

\section{Lessons Learned.}

In order to deal with the challenges more effectively, participants suggested that there be increased contact between the Brazilian scholar and supervisor, and the UA supervisor prior to the arrival of the scholar. In order to increase the contact prior to the program, participants suggested that a videoconference, or at least a phone conversation, between the supervisors and the scholar be arranged. During the videoconference research objectives and expectations of the scholar could be discussed. This video conference could be held one to two months prior to the scholar's arrival after all arrangements were confirmed. The videoconference would help to ensure the feasibility of the scholar's research plan and help both scholars and supervisors to plan their participation in the program. Supervisors and scholars discussed the importance of planning the VSP prior to the arrival of the scholar at UA:

I think that if I could have met with these students face-to-face first, it would have helped a lot because then we would have been able to work through a number of things, built a relationship that would allow them to work on something, and then connect us more by email so that they're really prepared by the time they get here (Supervisor \#8).

But we haven't done that, and you know, a phone conversation with our office, the person in Brazil, and the student or the scholar, and the supervisor here would probably be good prior to them coming (Supervisor \#12).

I think that having a preliminary contact established with the supervisor is fundamental. I think it's fundamental, it's no guarantee but it's very important because you already know how you work, he already reads the material you wrote, he already reads a short curriculum, you've already designed a sort of work plan, already said what you propose and what he can do (Visiting Scholar \# 5).

Some supervisors also proposed that they be supported and encouraged to go to Brazil when teaching opportunities existed to enhance the development of a collaborative relationship. One supervisor commented:

I would love to see some kind of funding available for faculty to actually go and stay for a term or stay for a semester and really become immersed. I think that would be a wonderful strength to add to the program somehow because I think we need better understanding and appreciation of their scenario and their situation. They come up here and stay with us for several months at a time, or even years, but we usually only go for very short periods of time (Supervisor \#2).

Another supervisor strongly believed that she should be part of the recruitment process: 
If I'm having a student, I want to know about the student, I want to communicate with the student, and I want to be part of the process that decides whether we're going to have that student or not...so often, the international decisions are taken without input from us, and I find that difficult (Supervisor \#11).

One scholar also suggested developing an activity program prior to their arrival to improve their preparation to improve the preparation of scholars:

The second suggestion is that, before the student travels, he could have a meeting either by skype or e-mail with the supervisor, with the staff from the Global Nursing Office there, with the staff from the international office here, to set up an activity program for this study, what is he interested in. Agreement with the people there of course. But that a program would be established in advance (Visiting Scholar \#10).

Many of the supervisors felt that they needed more preparation prior to supervising their Brazilian scholar. They needed to understand the project's purpose and be provided with the project guidelines:

It would have been helpful to sit down and speak to the coordinator of the program prior to receiving the scholar, and discuss the guidelines/expectations (Supervisor \#10).

I guess when I did this, certainly it was not explained to me there would be any expectation for any ongoing work together...But it was a big surprise to me when I found out that potentially, other people expected this to be an ongoing, long-term relationship because it wasn't explained to me that way at all (Supervisor \#5).

Further encouragement and preparation of faculty members at USP-EERP was also highly recommended:

And I think some suggestions I'd make, is that we could, that faculty could be included in this post-doctoral perspective before the vacancies were opened. That we could already have a culture, like, that this program exists, and that sooner or later you can apply, that we have the time to enjoy all these preparation phases, talking to the supervisor there (Visiting Scholar \#8).

But, perhaps, for example, as many faculty go there I am thinking that, perhaps, it would be interesting to have, I don't know, some material about the Canadian culture, to read in advance, to know how people think. Also to have a parameter on how to behave, in certain situations, like, when you're alone with local people (Visiting Scholar \#8).

In addition to planning strategies, several scholars and supervisors voiced concerns that " 6 months is a very short time" to meet the expectations of the program because adaptation to, and contact with a foreign language and culture was included in the 6 month period. Several scholars commented on the length of the VSP:

The partnership establishes six months [but] from my perspective, I stayed one year, I think six months is very short (Visiting Scholar \#9).

The only suggestion I have is exactly that, that the duration would be 1 year instead of 6 months. Because, really, at bottom, that's it, if the work is going to be productive, it will be from 1 year onwards. Unless you have preliminary research experience with them (Visiting Scholar \#12). 
Some supervisors also felt that it would be beneficial for the scholars to stay in Canada for at least one year:

Maybe it would be better to have them study only English for 6 months, and then do a 6month period with the supervisor. But the funds right now wouldn't cover that long, and most people would have trouble being away for a year. So it's kind of that balance: what works for most people (Supervisor \#12).

On the other hand, if scholars were to stay longer it would limit the number of scholars that could participate in the VSP and it would also be challenging for scholars to leave their work and families for a one year period. One scholar recommended that we:

Not be that strict, that closed on time. Because, sometimes, there are projects for which you can even stay less than 6 months and, depending on the study, the project you are going to develop there, you need more than 6 months (Visiting Scholar \#11).

\section{Discussion}

In general, scholars and supervisors found they had gained intercultural competencies through their participation in the VSP. In this context, within a cross-cultural learning process, participants felt they increased intercultural awareness and their capacity to act in a culturally diverse setting. In a study developed with faculty lecturers participating in an international exchange program, Enskar, Johansson, Ljusegren, and Widang (2011) also found the experience to be very positive and resulted in personal and professional growth, including the development of networks.

Several challenges related to initial acclimatization were highlighted by participants however, particularly related to language and accommodation issues. Wilson and colleagues (2013) also identified challenges related to language difficulties in an international leadership development program for nurses and other health workers. Despite the challenges, the authors concluded that the program provided opportunities for cross cultural sharing and interdisciplinary learning and collaboration among participants.

Verbal and non-verbal communication patterns are important features of culture and, within the VSP, the fact that many scholars did not speak fluent English was considered an initial barrier to their acclimatization to a different culture. Communication with local people was initially difficult for the scholars because their language skills for everyday life were insufficient. With time, scholars acquired the ability to communicate and began to understand aspects of the Canadian culture, which made them feel better adjusted to the new environment. However, in some cases communication difficulties can impair the development of intercultural competencies. Occasionally, these difficulties can lead to situations where students and scholars start to totally withdraw from interactions and ultimately become isolated (Koskinen \& Tossavainen, 2003; Ruddock \& Turner de, 2007).

Social interaction and language are vital for the intercultural awareness and maturation process, enabling the scholars' adjustment to differences. Therefore, it was important that scholars were coached to deal with cross language barriers and were able to engage in an English training program during their stay (Koskinen \& Tossavainen, 2004). The contribution of families to the adjustment process was discussed. Supervisors mentioned the loneliness felt by scholars when they came by themselves and the positive impact on adaptation when the scholars came 
with their families. Although they incurred more expenses, scholars were more confident to deal with different barriers when they had the personal support of family members.

In order to deal with these challenges, preparation was considered fundamental to aid the process of adjustment and acclimatization in Canada. Scholars and supervisors mentioned gaps in the initial phase of the program and emphasized the need for restructuring the process to ensure preparation was integrated into the VSP. In a study to evaluate a cross-cultural exchange program for European students, Koskinen and Tossavainen (2004) highlighted the importance of the orientation phase to prepare students to face differences in the host culture.

Furthermore, participants argued that preparation was an important phase in the crosscultural learning process and could make a huge difference to the outcomes of the international program. Heuer, Russell, and Kahlstorf, (1997) examined the impact of the total cultural immersion of seven nursing students from the USA in an international exchange to Russia. Before their experience, the students attended basic Russian language courses and classes that addressed their concerns about currency, the bartering system, cultural expectations and differences. This prior preparation was considered key to the successful adjustment of these students during their six-week placement. Cultural and language differences can be addressed through specific efforts including offering comprehensive orientations to enhance scholars and supervisors' self-awareness of their own culture, providing a deeper understanding of cultural differences, and offering specific knowledge of nursing practice and research in both countries (Yeom \& Bae, 2010).

In order to deal with potential problems, scholars and supervisors affirmed the need to have online meetings before the arrival of the scholars, in order to talk about the research proposal and the scholars and supervisors expectations regarding the program. One strategy some supervisors suggested was for them to go to Brazil to better understand the scholars and the context of their lives. They believed that this would enhance cross cultural learning and the acquisition of intercultural competencies. Considering that there are funds available from Brazilian financial agencies for visiting scholars, an increasing number of exchanges involving potential supervisors could be considered a feasible planning strategy in the future.

Despite not having a prior experience in Brazil, some supervisors mentioned that their participation in the program was fundamental to them, helping to influence their understanding of their own reality. Scholars also mentioned the richness of learning about other cultures and dealing with these differences in the supervision process. In this sense, dealing with cultural differences is considered a core factor in the development of intercultural awareness.

Participants recommended increasing the length of the program because six months was not enough time to finish the proposed research project and deal with the different challenges they faced in Canada. Nevertheless, there are few studies comparing the impacts of long-term and short-term programs, although an extension of their stay would enable them a deeper immersion in the host culture (Button et al., 2005).

Despite time constraints for both scholars and supervisors, the cultural immersion provided by participation in the VSP was an incredible opportunity to forge partnerships, friendships and enhance cultural sensitivity (Wood \& Atkins, 2006). In this context, learning through experience is considered to be more relevant and valuable than theory-based learning (Quinn \& Hughes, 2007), enabling scholars and supervisors to develop cultural sensitivity, enhance their leadership skills, and increase their knowledge and independent learning. 


\section{Limitations}

The interviews were conducted in both English and Portuguese. Although back translation was used to ensure that the transcription of the interviews was accurate, there may have been some errors in the translation and interpretation of the interviews. Although the VSP has continued for several years, the current evaluation was only carried out at one point in time. A final limitation is that visiting scholars were only from Brazil and there were no scholars recruited from Canada.

\section{Conclusions}

In this study, cross-cultural learning was a circular process that involved dealing with challenges, experiencing stress in a strange environment and building intercultural competencies by critically reflecting and dealing with differences (Ruddock \& Turner de, 2007). This process enhanced scholars and supervisors' awareness and sensitivity to cultural diversity and their openness to new cross-cultural experiences. These benefits will increase the ability to obtain funding and retain faculty in universities (Nick et al., 2012; Ronsten, Andersson, \& Gustafsson, 2005). Research on the development of cross-cultural learning skills is a recent development (Nowell, White, Mrklas, \& Norris, 2015). We hope that programs such as the VSP will contribute to positive organizational cultures by encouraging new candidates and new programs of this kind to emerge, increasing career satisfaction, boosting morale and self-confidence, and enhancing professional development. In addition to the benefits mentioned, it is to be expected that the VSP experience also enhanced the teamwork skills (Kanaskie, 2006) of supervisors and scholars at both institutions involved. 


\section{References}

Bennet, M. J. (1993). Towards ethnorelativism: a developmental model of intercultural sensitivity. In R. M. Paige (Ed.), Education for the Intercultural Experience. Yarmouth, ME: Intercultural Press.

Button, L., Green, B., Tengnah, C., Johansson, I. \& Baker, C. (2005). The impact of international placements on nurses' personal and professional lives: literature review. Journal of Advanced Nursing, 50(3), 315-324. doi:https://doi.org/10.1111/j.13652648.2005.03395.x

Choi, J., Kushner, K. E., Mill, J., \& Lai, D. (2012). Understanding the language, the culture, and the experience: translation in cross-cultural research. International Journal of Qualitative Methods, 11(5), 652-665.

Enskar, K., Johansson, I., Ljusegren, G., \& Widang, I. (2011). Lecturers' experiences of participating in an international exchange. Nurse Education Today, 31(6), 541-546. doi:https://doi.org/10.1016/j.nedt.2010.10.018

Hagen, L., Munkhondya, B., \& Myhre, K. (2009). Similarities and mutual understanding: exchange experiences in Malawi for host and guest students. International Nursing Review, 56(4), 476-482. doi:https://doi.org/10.1111/j.1466-7657.2009.00744.x

Heuer, L., Russell, L., \& Kahlstorf, H. (1997). Short-term cultural immersion in Russia. Prairie Rose, 66(1), 7-11.

Kanaskie, M. L. (2006). Mentoring--a staff retention tool. Critical Care Nursing Quarterly, 29(3), 248-452. doi:https://doi.org/10.1097/00002727-200607000-00010

Koskinen, L., Campbell, B., Aarts, C., Chasse, F., Hemingway, A., Juhansoo, T., ... Nordstrom, P. M. (2009). Enhancing cultural competence: trans-atlantic experiences of European and Canadian nursing students. International Journal of Nursing Practice, 15(6), 502-509. doi:https://doi.org/10.1111/j.1440-172x.2009.01776.x

Koskinen, L., \& Tossavainen, K. (2003). Relationships with undergraduate nursing exchange students--a tutor perspective. Journal of Advanced Nursing, 41(5), 499-508. doi:https://doi.org/10.1046/j.1365-2648.2003.02562.x

Koskinen, L., \& Tossavainen, K. (2004) Study abroad as a process of learning intercultural competence in nursing. International Journal of Nursing Practice, 10(3), 111-20. doi:https://doi.org/10.1111/j.1440-172x.2004.00470.x

Kuehn, A. F., Chircop, A., Downe-Wamboldt, B., Sheppard-LeMoine, D., Wittstock, L., Herbert, R., ... Critchley, K. (2011). Evaluating the impact of a North American nursing exchange program on student awareness. International Journal of Nursing Education Scholarship, 8(1), 1-15. doi:https://doi.org/10.2202/1548-923x.1919

Kulbok, P. A., Mitchell, E. M., Glick, D. F., \& Greiner, D. (2012). International experiences in nursing education: a review of the literature. International Journal of Nursing Education Scholarship, 9, 1-21. doi:https://doi.org/10.1515/1548-923x.2365

Mill, J. E., Johnson, L. C., Mendes, I. A. C., Ventura, C. A. A., \& Brito, E. S. (2014). A qualitative evaluation of a visiting scholar program between Brazil and Canada. Journal of Nursing Education and Practice, 4(3), 252-264. 
Mill, J. E., Mendes, I. A C., Ventura, C. A. A., Johnson, L. C., Kliachik, D., \& Brito, E. S. (2012). Evaluation of the Visiting Scholar Program. Unpublished Report, Edmonton, AB: Faculty of Nursing, University of Alberta.

Morse, J. M. (1994). Emerging from the data: The cognitive processes of analysis in qualitative inquiry. In J. M. (Ed), Critical issues in qualitative research methods (pp. 23-43). Thousand Oaks, CA: Sage.

Nick, J. M., Delahoyde, T. M., Del Prato, D., Mitchell, C., Ortiz, J., Ottley, C., ... Siktberg, L. (2012). Best practices in academic mentoring: a model for excellence. Nursing Research and Practice, 937906. doi:https://doi.org/10.1155/2012/937906

Nowell, L., White, D. E., Mrklas, K., \& Norris, J. M. (2015). Mentorship in nursing academia: a systematic review protocol. Systematic Reviews, 4, 16. doi:https://doi.org/10.1186/s13643-015-0007-5

Purnell, L. D., \& Paulanka, B. (1998). Transcultural health care: A culturally competent approach. Philadelphia, PA: FA Davis CO.

Quinn, F. M., \& Hughes, S. J. (2007). Quinn's principles and practice of nurse education (5th edition). Cheltenham, UK: Nelson Thornes.

Ronsten, B., Andersson, E., \& Gustafsson, B. (2005). Confirming mentorship. Journal of Nursing Management, 13(4), 312-21. doi: https://doi.org/10.1111/j.13652934.2005.00541.x

Ruddock, H. C., \& Turner de, S. (2007). Developing cultural sensitivity: nursing students' experiences of a study abroad programme. Journal of Advancing Nursing, 59(4), 361-9. doi:https://doi.org/10.1111/j.1365-2648.2007.04312.x

Sandelowski, M. (2000). Whatever Happened to Qualitative Description? Research in Nursing \& Health, 23, 334-40. doi:https://doi.org/10.1002/1098-240x(200008)23:4<334::aidnur9>3.0.co;2-g

Smith, P. B., Bond, M. H., \& Kâğıtçıbaşı, Ç. (2006). Understanding social psychology across cultures: Living and working in a changing world. London, UK: SAGE Publications Ltd.

Wilson, L. A., Crooks, E. A., Day, S. W., Dawson, M. A., Gakumo, C. A., Harper, D. C., ... Theus, L. H. (2013). Global perspectives on nursing leadership: Lessons learned from an international nursing and health care leadership development program. Journal of Nursing Education and Practice, 4(2), 140. doi:https://doi.org/10.5430/jnep.v4n2p140

Wood, M. J., \& Atkins, M. (2006). Immersion in another culture: one strategy for increasing cultural competency. Journal of Cultural Diversity, 13(1), 50-4.

Yeom, H. S., \& Bae, H. (2010). Potential issues in field practicum student exchange between Korea and the USA. International Social Work, 53(3), 311-326.

doi:https://doi.org/10.1177/0020872809359748 